\title{
Diseño de proyectos con bambú en Lima como estrategia de difusión de un método constructivo alternativo y sostenible
}

Projects design with bamboo in Lima as a strategy for
dissemination of an alternative and sustainable constructived method

Recibido: febrero 11 de 2017 | Revisado: marzo 10 de 2017 | Aceptado: mayo 15 de 2017

\begin{abstract}
YANN BARNET ${ }^{\mathrm{I}}$ RESUMEN
FAOUZI JABRANE $^{2}$ En el marco de su misión de innovación para el desarrollo sostenible, el Instituto de Vivienda, Urbanismo y Construcción (IVUC) de la Universidad de San Martín de Porres ha asumido un rol preponderante en el sector de la construcción eco-amigable a base de bambú, puesto que utiliza una especie nativa del Perú, la Guadua angustifolia, comúnmente, llamada caña Guayaquil. Los proyectos, elaborados con ONGs y el sector público, tienen un alto componente social y, a la vez, se hallan en la búsqueda de nuevas formas eficientes y sismorresistentes de utilizar este material y así ampliar, paulatinamente, los conocimientos y ejemplos sobre la arquitectura con bambú. En un afán de mostrar las posibilidades de este material y cambiar el paradigma de su de uso temporal, dirigido hacia un público masivo de escasos recursos, el IVUC ha diseñado sus últimos proyectos en espacios de alta visibilidad en Lima, capital del Perú.
\end{abstract}

Palabras claves: arquitectura sostenible, bambú, vivienda social, construcción alternativa

\begin{abstract}
Within the framework of its mission of innovation for sustainable development, the Institute for Housing, Urbanism and Construction (IVUC) of the University of San Martin de Porres has assumed a leading role in the field of bamboo based ecofriendly construction, using a native specie from Peru, the Guadua Angustifolia, usually known as Guayaquil cane. The projects with involvement from both ONGs and governmnent institutions have a considerable social component and at the same time, are in the search for new both efficient and earthquake resistant ways to use this material and thus, slowly increase the knowledge about and create examples of bamboo based architecture. In an effort to show the possibilities of this material and to change the paradigm of its temporary uses, directed towards an audience of limited resources, IVUC has designed its latest projects in high visibility areas in Lima, capital city of Perú.
\end{abstract}

Key words: sustainable architecture, bamboo, social housing, alternative construction 


\section{El bambú en el contexto peruano: un aprovechamiento por potenciar}

El bambú no es un árbol, sino una gramínea (familia Poaceae) que se puede asimilar a un pasto gigante. Pertenece a la subfamilia de los Bambusoideae que cuenta con, aproximadamente, 1400 especies alrededor del mundo (Londońo, 2005), y de 100 de ellas se encuentran en el Perú, por lo tanto, es uno de los países que presentan mayor diversidad.

Dentro de los bambúes presentes, sobresale la especie "Guadua angustifolia, seleccionada como una de las 20 mejores del mundo por sus excelentes propiedades físico-mecánicas, su gran tamaño (20-30m) y por su comprobada utilización en la industria de la construcción y en la industria de pisos, paneles y aglomerados" (Añazco, 2013). Por su ligereza y su flexibilidad, constituye también una excelente alternativa para construir edificios sismorresistentes, criterio clave para todas las poblaciones que viven en zonas de riesgos sísmicos altos.

Si bien, en el Perú, existen grandes cantidades de guaduales (terrenos poblados de Guadua), la especie Guadua angustifolia Kunth es, comúnmente, conocida como caña Guayaquil, porque una gran parte de los tallos que se utilizan provienen de la región sur del Ecuador. De hecho, en el año 2005, el gobierno del Ecuador realizó un estudio para conocer sus exportaciones de bambú en el cual se destacó que $93 \%$ de las exportaciones de bambú se realizaron hacia el Perú (CORPEI - CBI, 2005) (Banco Central del Ecuador). En aquel año, se estimó que se importaba, anualmente, alrededor de 12 000000 tallos de Guadua angustifolia.
Aun si la importación de bambú desde Ecuador sigue masiva y principalmente informal, la cadena productiva nacional está aumentando: entre los años 2012 y 2014, la producción anual ha superado los 700000 tallos (Ministerio de Agricultura y Riego, 2014) (Ministerio de Agricultura y Riego, 2013; Ministerio de Agricultura y Riego, 2015), lo que demuestra que la oferta, en el mercado, se está consolidando.

En el territorio peruano, si bien existe presencia de esta especie, en la mayoría de los departamentos de la selva, las plantaciones que abastecen el mercado nacional han sido instaladas casi en su totalidad en las provincias del Nororiente del país, en las regiones de Cajamarca, Lambayeque, Piura y Amazonas, principalmente en las zonas medio y altas de las cuencas. (Espinoza, 2015).

Por la cercanía del recurso, es en la región norte del Perú donde se encuentra el mayor uso de la guadua en la construcción, sea bajo su forma rolliza o como caña chancada. Sin embargo, el uso global del bambú, en la construcción, sigue muy limitado: según el último censo del año 2007 sobre las viviendas particulares realizado a nivel nacional, menos de $7.2 \%$ de ellas son susceptibles de integrar bambú en sus paredes, sumando las viviendas con paredes de quincha (1.97\%) y las viviendas con otros tipos de materiales (caña partida, carrizo, otro) (INEI, 2008).

En un estudio que se realizó en 2013, en el que se analizó el uso del bambú en las viviendas, se destacó que "ha cambiado bastante su papel en la construcción, pasando de un material que tuvo un pa- 
pel importante en la quincha de viviendas de clases sociales media y alta, a un material destinado a la autoconstrucción de las clases sociales bajas" (Barnet \& Jabrane, 2013). En el competitivo mercado inmobiliario, el bambú está ubicado en un círculo vicioso que lo limita como alternativa constructiva creíble y masiva. Cada eslabón de la cadena productiva actual del bambú, presenta importantes carencias que afectan su calidad, y por ende, deterioran su imagen. Hoy en día, el mal uso del bambú no alienta una demanda más exigente que sería capaz de financiar y alentar una mejoría de la calidad de la oferta. (Barnet \& Jabrane, 2013). ( Figura 1).

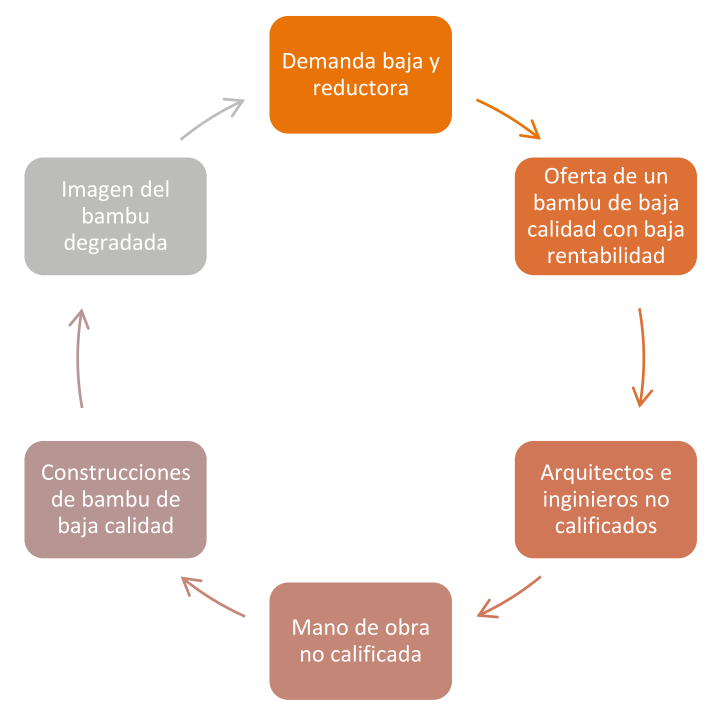

Figura 1. El círculo vicioso de la cadena productiva del bambú

A pesar de esas dificultades, es notable la creciente necesidad de utilizar materiales amigables con el ambiente en la construcción, y la búsqueda, en la arquitectura, de responder cada vez más a criterios de sostenibilidad. En el contexto del Perú, que cuenta con el recurso en varias de sus regiones, el bambú debería volverse una gran herramienta, ya que es un recurso altamente renovable, que presenta una de las huellas ecológicas más bajas dentro de los materiales de construcción. En un estudio comparativo sobre los materiales, Janssen evalúa el ratio entre la cantidad de energía que se requiere para fabricar un material y su resistencia estructural (unidad de comparación utilizada: $\mathrm{MJ} / \mathrm{m}^{3} \mathrm{X} \mathrm{N} /$ $\mathrm{mm}^{2}$ ). Concluye que el orden de magnitud de lo que consume el bambú es 50 veces inferior a lo que consume el acero (Janssen, 1981). Si bien es cierto existen otros criterios que entran en juego como los procesos de obra o el ciclo de vida del material, no cabe duda que el bambú constituye una forma de reducir, sustancialmente, el impacto de una edificación sobre el medio ambiente.

Por razones técnicas, ambientales, sociales y económicas, a las cuales los diseñadores deben añadir un valor estético, hoy en día no cabe duda que el bambú es un material del presente y futuro en el sector industrial y en particular, en el campo de la construcción que consume una gran cantidad de materiales, por lo cual es urgente experimentar, innovar y difundir nuevas tecnologías de uso y transformación del bambú en una búsqueda de potenciar una cadena productiva sostenible y a la vez "extender y renovar una tradición constructiva en el Perú". (Barnet \& Jabrane, 2013).

\section{Los avances y aspectos positivos en la cadena productiva del bambú actual en el Perú}

Si bien, en el año 2017, el uso del bambú en la construcción y la industria en general, está muy limitado; sin embargo, en esta última década, han surgido numerosas iniciativas que están fomen- 
tando bases favorables para un desarrollo duradero de la cadena productiva.

Desde el sector público, se promulgó, en el año 2008, el decreto Supremo $\mathrm{N}^{\circ}$ 004-2008- AG, que declara de interés nacional la instalación de Plantaciones de Bambú y Caña brava. Este interés simbólico se ha ido consolidando, paulatinamente, con políticas de promoción lideradas, principalmente, por el Ministerio de Agricultura y Riego que cuenta con un Plan Nacional de Promoción del Bambú 20082020 tiene como objetivos generales, "promover el desarrollo de plantaciones de bambú, en el territorio nacional bajo un enfoque de sostenibilidad socioeconómica y ambiental, contribuyendo a la mejora de las condiciones de vida del poblador rural, la equidad de género, la lucha contra la pobreza y el combate contra la tala ilegal, la deforestación y el desarrollo de los cultivos de productos ilícitos." (Ministerio de Agricultura, 2008).

Por otro lado, en el sector de la construcción, el Ministerio de Vivienda, Construcción y Saneamiento (MVCS) marcó un gran paso con la formulación de una norma para las edificaciones sismorresistentes con bambú (Ministerio de Vivienda, Urbanismo y Construcción, 2012) que fue aprobada en el año 2012. Cabe mencionar que como expertos del IVUC participamos en el Comité de elaboración de dicha norma, compartiendo nuestra experiencia de construcciones sismorresistentes en bambú, desarrollada como consecuencia del terremoto de Pisco, año 2007 (en colaboración con la Comisión Episcopal de Acción Social). Esta norma permite al sector de la construcción del Perú, contar con un instrumento técnico-legal que permita promo- ver las edificaciones formales con el uso del bambú para edificaciones de hasta dos pisos.

Esos avances, en el sector público, han sido apoyados por la Red Internacional del Bambú y Ratán (INBAR), a la cual pertenece el Perú como país fundador, cuyas acciones de capacitación, promoción y ejecución de proyectos pilotos han permitido consolidar el sector. En particular, el INBAR, en sociedad con las ONG Cicap en Lambayeque, y Progreso en Piura, desarrolló capacidades y experiencias de manejo sostenible de la Guadua Angustifolia con comunidades campesinas de las regiones correspondientes, que se han vuelto capaces de ofrecer al mercado un producto de calidad que responde a los criterios mínimos de la Norma de Edificación E100 Bambú. (Figura 2)

Además de los esfuerzos institucionales, se van sumando numerosas iniciativas del sector privado en los campos de la silvicultura, eco-turismo, artesanía, fabricación de productos de consumo, etc. En cuanto a la transformación industrial masiva, existen todavía grandes oportunidades por desarrollar, que se pueden apoyar en las experiencias exitosas de otros países de la región como Ecuador donde se está desarrollando la producción de tableros y perfiles o Brasil que fabrica pulpa de papel con bambú.

De todos modos, resulta importante multiplicar los usos que se dan al bambú con la finalidad de obtener provecho de todas sus partes (culmo, hojas, raíces) y evitar cualquier tipo de desperdicios. En este ámbito, la fabricación de carbón de bambú, resulta un método muy interesante ya que permite dar un uso com- 
pleto a los retazos generados para otros beneficios.

En la arquitectura, la cadena productiva se basa, principalmente, en una utilidad muy primitiva del material donde las infraestructuras turísticas (restauran- tes, hotel de playa, ecolodge) son casi las únicas, en las cuales se pone en valor el bambú como material de construcción. Por lo tanto, existe una necesidad de ampliar, considerablemente, los campos de usos en la construcción.

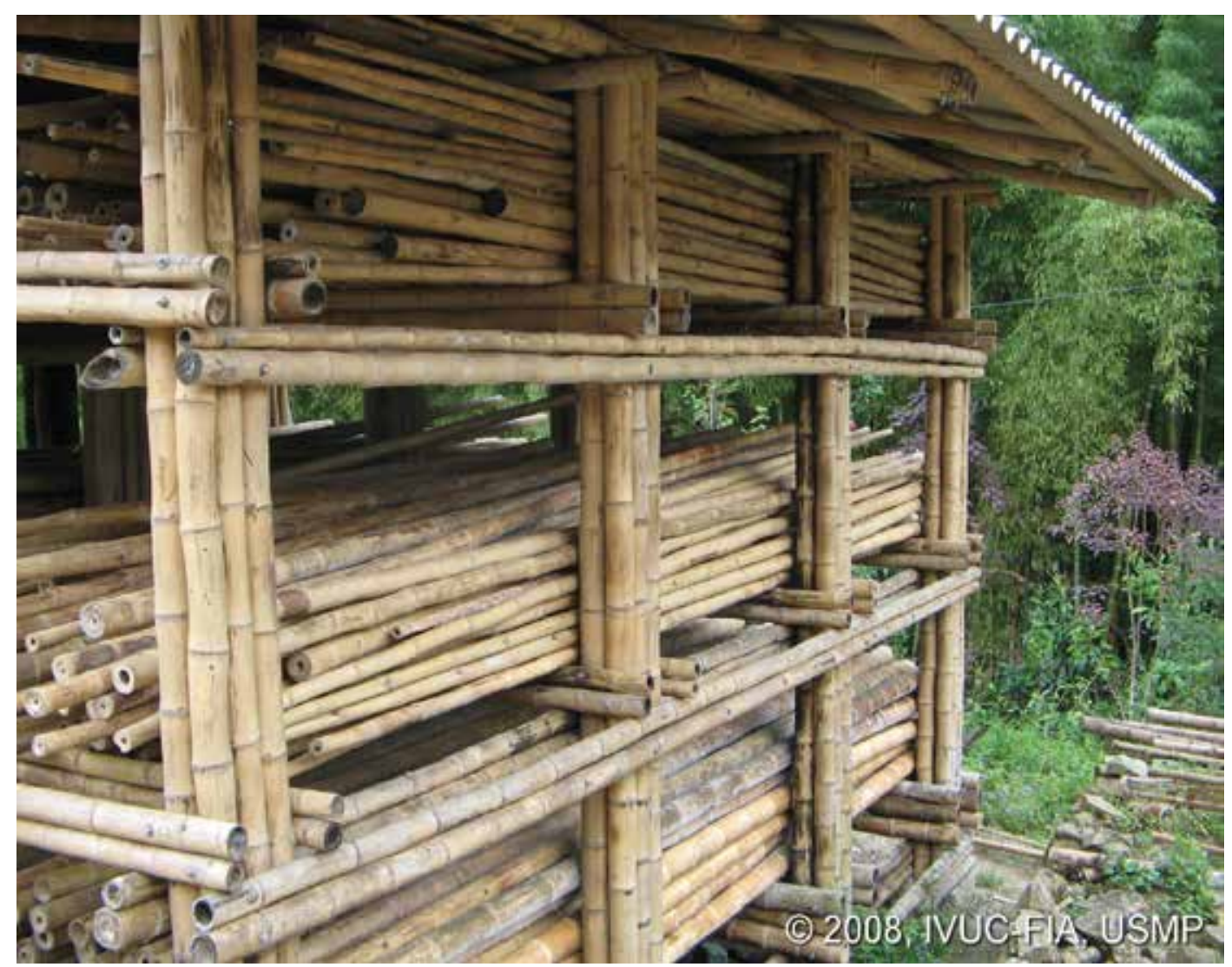

Figura 2. Almacén de bambú Guadua Angustifolia inmunizado y secado. Productores del distrito de La Florida - Lambayeque. Proyecto de la ONG CICAP

\section{Promover el uso del bambú a través del desarrollo de modelos de vivienda social}

\section{Conceptualización y diseño}

Como respuesta al desafío de masificar el uso del bambú en el sector de la construcción, el IVUC se propuso como meta introducir el uso de la Guadua angustifolia dentro de la vivienda social, ya que este sector constituye un mercado muy importante $y$, a la vez, responde a la problemática nacional de mejorar las condiciones de vida de la poblaciones más vulnerables.

En este sentido, el IVUC pudo apoyarse sobre las experiencias exitosas que desarrolló, en el marco del programa transitorio de reconstrucción post terremoto, ejecutado por la Comisión Episcopal de Acción social durante el cual se apoyaron a familias damnificadas en la región de Pisco. En esta oportunidad, el IVUC desarrolló una propuesta integral de alterativa constructiva sismorresisten- 
te y económica a base de estructuras de bambú. Dentro de los proyectos elaborados, se puede mencionar la iglesia de la compañía de Jesús en Pisco y 54 módulos de vivienda de $22 \mathrm{~m}^{2}$ (Figura 3) (Comisión Episcopal de Acción Social, 2009). Dichos proyectos fueron diseñados en base a componente constructivos que se pudieran prefabricar en un taller y ser montado de forma muy rápida en la obra. Después de un proceso de experimentación y capacitación, se logró un sistema de construcción a base de pórticos y paneles de bambúes empernados con varillas roscadas de $3 / 8$ " que se prefabricaban con un equipo de dos o tres personas en el piso. De esa manera, se logró una considerable ganancia en término de productividad y calidad de ensamblajes, en comparación a un montaje in situ tradicional. Con un equipo experimentado, la construcción del módulo de vivienda de $22 \mathrm{~m}^{2}$ se realizaba, en una semana, luego del vaciado de los sobrecimientos para un equipo de cuatro personas. A modo de ejemplo de buenas prácticas, los planos de este módulo han sido introducidos en el anexo de la Norma E100.
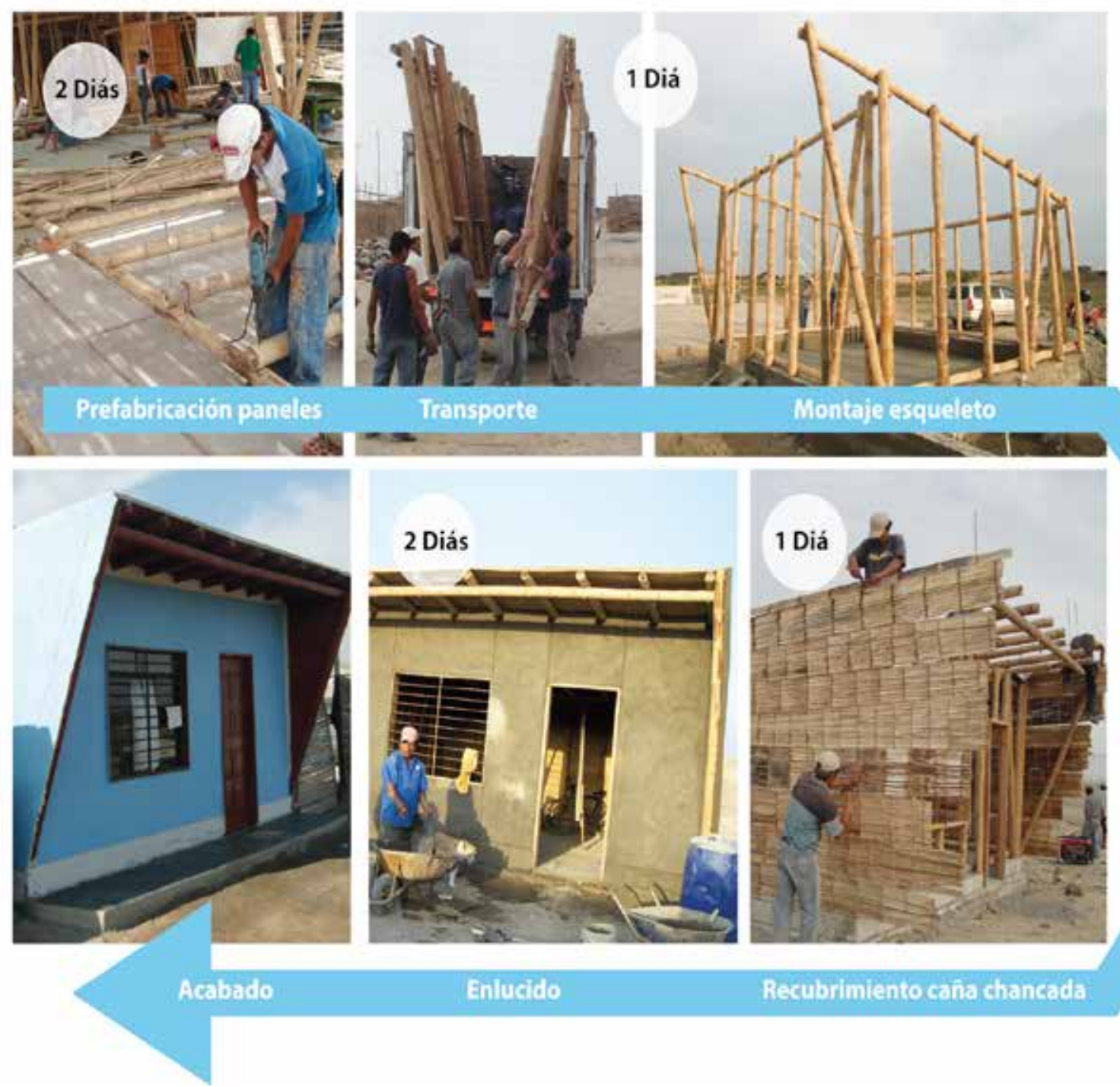

Enlucido

Recubrimiento cana chancada

Figura 3. Proceso de construcción del Módulo de Vivienda de $22 \mathrm{~m}^{2}$ 
Basándose en el éxito de esta experiencia de modelos de construcción sismorresistente de bajo costo para las familias damnificadas del terremoto, el IVUC desarrolló tipologías de vivienda social individual y de carácter progresivo que cumpliera con las exigencias del programa Techo Propio del MVCS. El hilo director de la conceptualización de los proyectos es crear una arquitectura a base de elementos que se puedan prefabricar en serie, sin perder la flexibilidad necesaria para adaptarse a las necesidades de cada familia. Rompiendo con los métodos tradicionales de construcción y los empalmes artesanales, los diseños se basan en sistemas de uniones con pernos y piezas metálicas que permiten facilitar los procesos de construcción, obtener el mejor provecho del material y abaratar los costos de mano de obra.

Desde el año 2013, el equipo ha recibido varios premios en el concurso anual "Construye para Crecer" que tiene como objetivo crear un banco de proyectos con una arquitectura adaptada a distintos climas del Perú. Las propuestas del IVUC, utilizando el bambú como elemento estructural, fueron galardonadas en las categorías de costa y selva, con materiales tradicionales, así como en la Categoría "Ecoamigable", que generan un precedente en la reflexión sobre alternativas de vivienda social sostenible construidas con bambú (Ministerio de Vivienda, Construcción y Saneamiento, 2014).

El proyecto que ilustra con más claridad este concepto es la Casa Costa Central cuya estructura portante está compuesta de paneles de bambú estandarizados de $1.2 \mathrm{~m}$ de ancho por dos pisos de alto (Figuras 4 y 5). Su cobertura está estructurada por dos domos muy fáciles de construir y transportar constituidos de una malla de latillas de bambú que reposan sobre un marco de bambú que sirve también para amarrar los paneles portantes entre sí. Debido a su geometría, este proyecto modular ofrece una gran flexibilidad de uso y permite el crecimiento de la vivienda, tanto horizontal como vertical y así brindar una estructura de doble altura prevista para poder recibir un entrepiso así como dispositivos desmontables y reutilizables en las nuevas extensiones (paneles de fachada, puertas, escalera). Con sus características, el proyecto se inscribe dentro del proceso de construcción progresiva para la vivienda social unifamiliar. El modelo es una solución constructiva respetuosa del medio ambiente e idónea para las zonas costeras con un suelo de baja capacidad portante. 

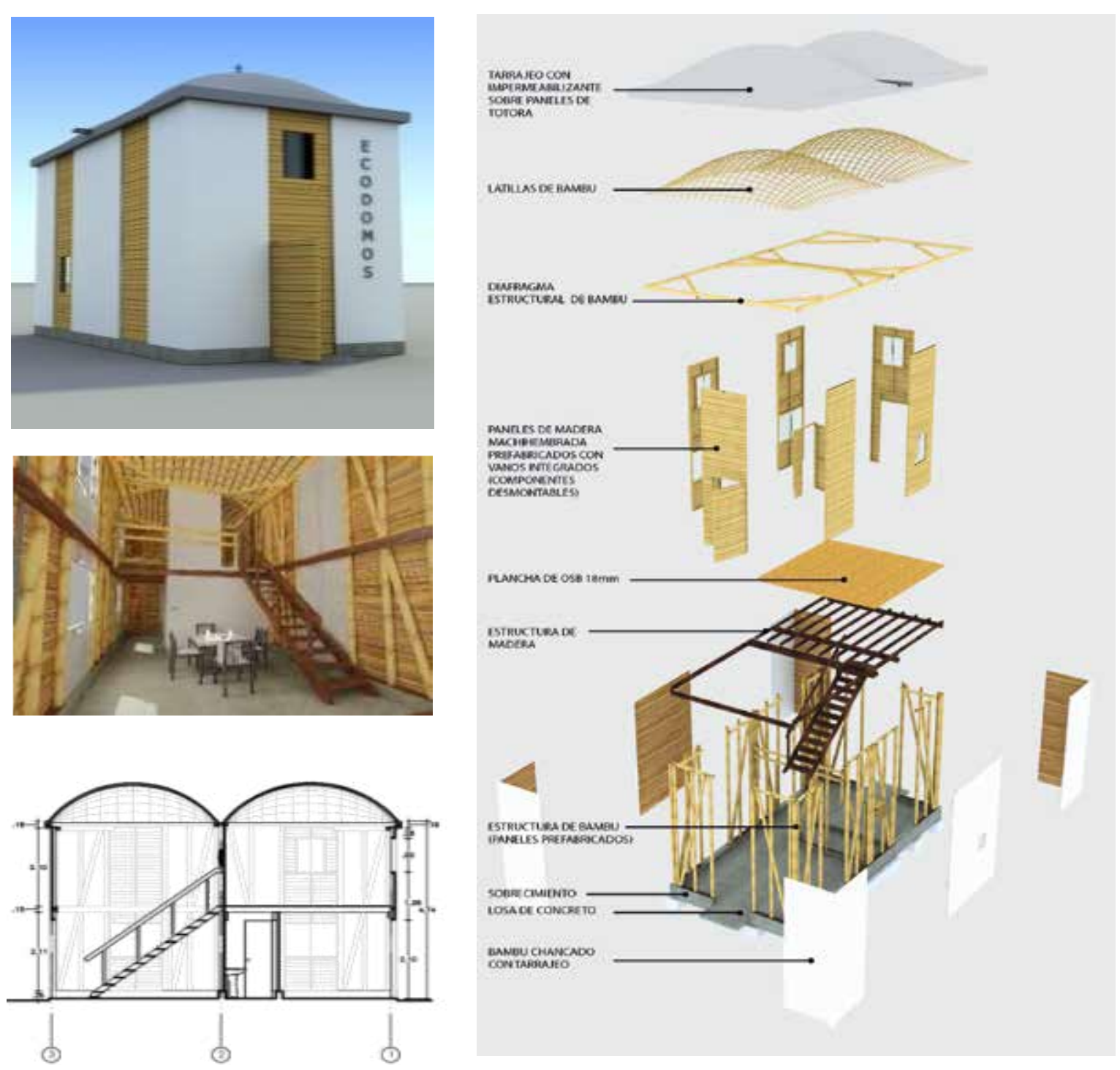

Figura 4. Ilustraciones de la Casa Costa Central del IVUC, segundo puesto del Concurso Construye para Crecer, categoría costa con materiales tradicionales

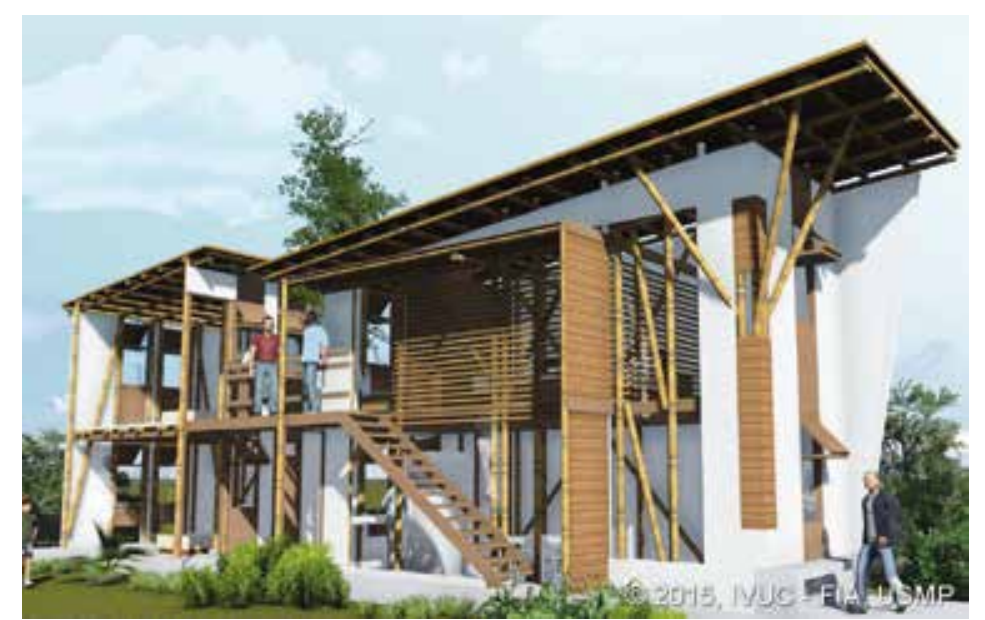

Figura 5. Propuesta de Casa Costa Norte del IVUC, primer puesto del Concurso Construye para Crecer 2014, Categoría Ecoamigable 


\section{Construcción de los primeros prototipos}

Pasar de la conceptualización de nuevos modelos con bambú hacia su materialización en un mercado dominado por la albañilería y el concreto no es tarea fácil. Aunque los diseños realizados hayan sido premiados en concursos nacionales e internacionales (Mención honrosa en " $\mathrm{Al}$ ternativas para vivienda popular para América Latina y el Caribe" organizado por The International Alliance of Inhabitants), todavía falta superar unos prejuicios sobre el bambú, visto por la mayoría como un material de pobres, temporal, y a lo mejor rústico. Por esas razones, resultaba importante para el equipo del IVUC construir unos prototipos de sus propuestas en Lima, y así enseñar a través del ejemplo que se puede utilizar el bambú de forma efectiva en la estructura de viviendas.

Durante la Feria Internacional de la Construcción EXCON 2013, se ofreció la oportunidad de construir, por primera vez, un prototipo de la Casa Selva, dando a conocer a un público masivo las bondades del bambú como material de construcción. El módulo de la casa de dos pisos con una base de $4 \times 4 \mathrm{~m}$ fue adaptado a las exigencias de un estand de feria desmontable que tenía que construirse en solo cinco días. Esta primera experiencia de construcción permitió comprobar la factibilidad de la propuesta, ajustar cálculos de costos y, a la vez, mejorar unos detalles constructivos. Dentro de las conclusiones de esta primera experiencia construida, se puede resaltar que el uso del bambú para un segundo piso resulta una solución idónea ya que permite realizar una estructura de muy bajo peso y ofrece posibilidades de aleros importan- tes con una estructura sencilla y económica comparada a otros materiales como la madera o el acero. Las más de 5000 personas que acudieron a la feria demostraron, a la vez, curiosidad por la propuesta y quedaron gratamente sorprendidos por las posibilidades arquitectónicas y estructurales del bambú, ya que era la primera vez que se presentaba como un material de construcción contemporáneo en un evento de esta magnitud.

En el año 2014, el Ministerio del Ambiente invitó a la Universidad de San Martín de Porres a construir dos módulos de la Casa Selva como modelo de construcción sostenible en el Marco de la Exhibición Voces por el Clima durante la COP 20 Lima, ofreciéndonos la oportunidad de demostrar la capacidad de crecimiento progresivo del proyecto con un segundo módulo que se acopla al primero conectando sus techos respectivos. Durante ese evento internacional, "La Casa Selva" albergó la muestra de la USMP (Figura 6): "Nuestros compromisos, una gestión responsable" que expuso los proyectos e iniciativas que se están desarrollando en nuestra casa de estudio como estrategias de desarrollo sostenible y medidas de adaptación al cambio climático. La construcción a cargo del equipo del IVUC duró dos semanas y el desmontaje duró dos días. La curiosidad y el interés demostrado por un amplio público proveniente del mundo entero probaron la creciente apertura hacia este tipo de alternativas de construcción sostenible y la feria ofreció un escenario único para promover el uso del bambú a los funcionarios de toda la región andina que acudieron a la COP 20. Cabe mencionar que en esta ocasión, la cobertura del techo sostenido por la estructura de bambú 
está constituida de una capa de esteras y de planchas acanaladas de polialuminio, fabricadas por Cartotek con el reciclado de envases de la empresa TetraPak.

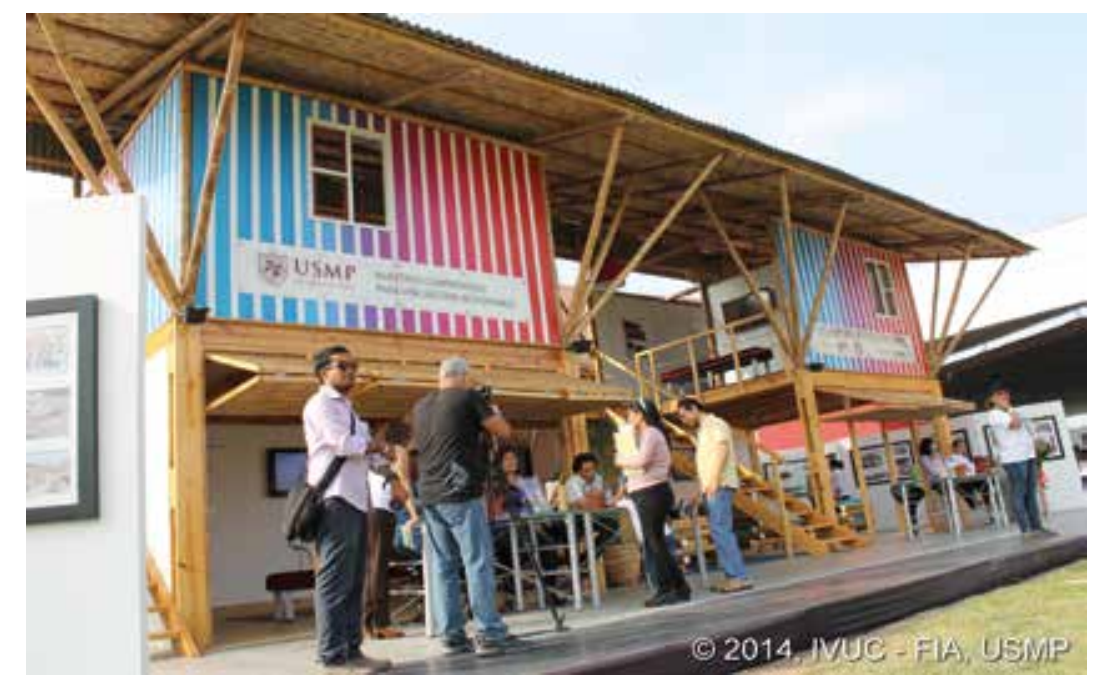

Figura 6. Stand Casa Selva en la Feria "Voces por el clima"

Aparte del gran impacto en cuanto al público concientizado durante los eventos mencionados anteriormente, una parte de los materiales del último prototipo fue donado, posteriormente, a la ONG Socios en Salud, quien tiene un programa de mejoramiento de las condiciones de las viviendas de pacientes que sufren de tuberculosis. En esta ocasión, el IVUC adaptó el diseño a las condiciones del lote de una familia necesitada del distrito de San Juan de Lurigancho en Lima (Figura 7) y con el esfuerzo de todos, incluyen- do el Comité de Responsabilidad Social Empresarial de la USMP, se pudo concretar su construcción lo que demostró el carácter versátil de la propuesta, y ofreció alternativas de construcción seguras de bajo costo para las poblaciones vulnerables que viven en las franjas marginales de las ciudades. Este proyecto, construido para ser permanente, va a servir de testigo en cuanto al comportamiento en el tiempo de una estructura de bambú, cuyo mantenimiento va a ser mínimo por la falta de recursos de la familia.

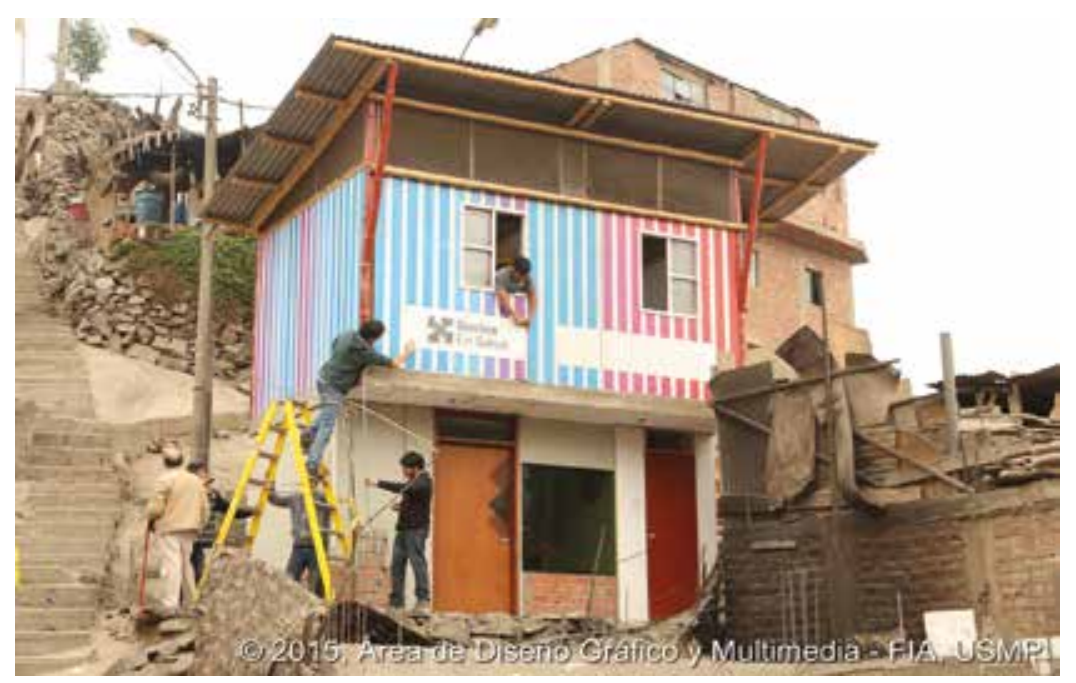

Figura 7. Casa de la familia Atalaya Antay en San Juan de Lurigancho, Lima 


\section{Promover el bambú a través de los espacios públicos}

\section{Exploración de nuevas tipologías de equipamiento público en el parque ecológico voces por el clima de Surco, Lima}

El riesgo de utilizar, únicamente, el bambú para viviendas económicas es encasillarlo en un uso básico y fortalecer su imagen de material asociado a la pobreza. Para romper este paradigma, el IVUC y sus socios han ido buscando construir edificaciones emblemáticas de alta visibilidad que se vuelvan objetos de promoción durables del bambú.

Esta estrategia se concretó con el Parque Ecológico Voces por el Clima en Lima, un proyecto de espacio público cuyo objetivo es concientizar al público sobre los desafíos del cambio climático en continuidad con las acciones de la COP 20. Por el carácter de ser un espacio pedagógico sobre el ambiente y el desarrollo sostenible, basado en pabellones temáticos, este parque pionero en América Latina constituía un escenario perfecto para la promoción del bambú y su uso en las edificaciones planteadas. De hecho, el éxito del prototipo de la Casa Selva en la feria Voces por El Clima, despertó el interés por parte de los actores públicos en integrar el bambú dentro las construcciones de este nuevo parque.

Con la colaboración del MINAM y el financiamiento de la Unión Europea, el INBAR, con el asesoramiento técnico del IVUC, propuso construir un auditorio con estructura de bambú, una casa demostrativa con sistema constructivo bahareque (tipo de quincha con bambú), y dos kioscos móviles. Esas tres obras, de formas y usos muy distintos, buscan enseñar la gran versatilidad y potencial del bambú en el sector de la construcción en el Perú.

Los bambúes utilizados para la construcción provinieron de productores de la Región Norte del Perú, y pasaron por un proceso de selección, inmunización y secado de acuerdo con los requisitos de la Norma E100. El parque, totalmente abierto al público, fue inaugurado el 21 de diciembre del año 2015 por el ministro del Ambiente, Manuel Pulgar Vidal, en compañía del alcalde de Surco, Roberto Gómez. Actualmente, el número de visitantes semanal supera las mil 200 personas, en su mayoría, estudiantes de los colegios de Surco así como de los distritos de la capital (Surco Mi hogar, 2016), convirtiendo este parque en uno de los grandes embajadores de la promoción del bambú, en la construcción a nivel nacional y regional, sobre todo, hacia los jóvenes que se convertirán pronto en la generación activa del país. Gracias a esta infraestructura pública y la apuesta de construir infraestructuras demostrativas y ejemplares del usos del bambú en la construcción, se puede estimar que unas 100000 personas han sido concientizadas desde la apertura del parque. (Figura 8)

Cabe resaltar que uno de estos proyectos, la casa demostrativa de bambú ha sido replicada en un parque de la ciudad de Quito (capital del Ecuador) en la ocasión de Hábitat III, las conferencias de las Naciones Unidas sobre vivienda y desarrollo urbano sostenible, ampliando así, la visibilidad de la propuesta a nivel mundial. 


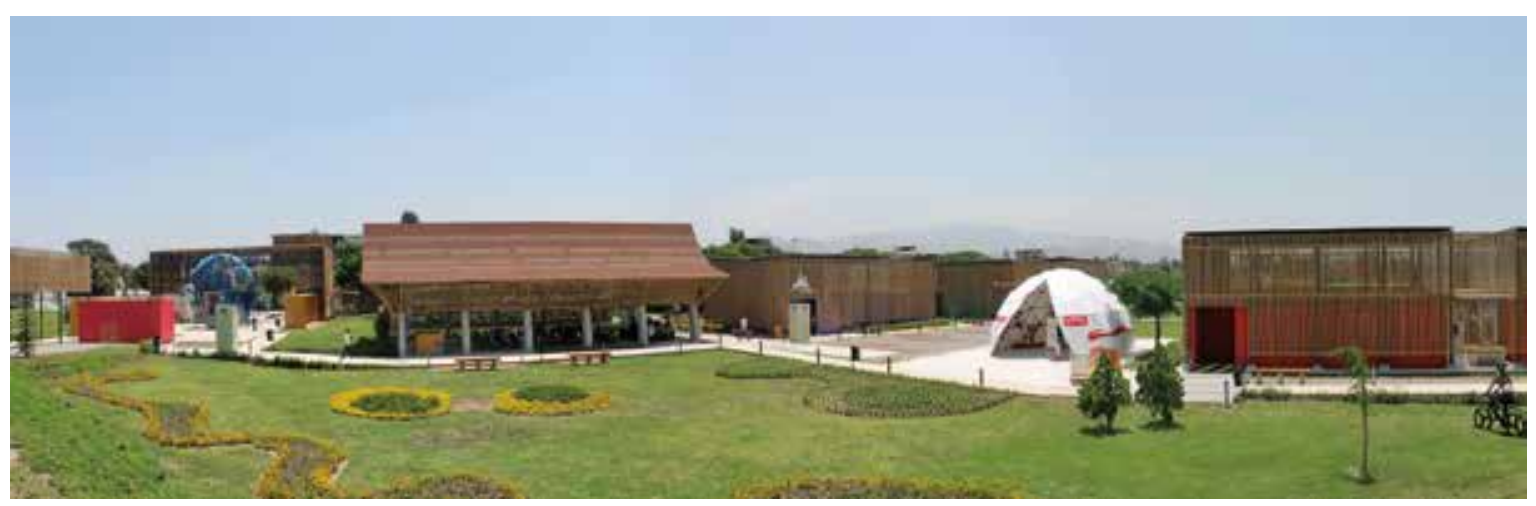

Figura 8. Fotografía del Parque Voces por el Clima en Surco, Lima, 2016

\section{Auditorio de bambú Voces por el Clima}

Área construida: $336 \mathrm{~m}^{2}$

Diseño: Arquitectos Yann Barnet y Faouzi Jabrane del IVUC - FIA, USMP.

Cálculo estructural: Ing. G Tello y Ing J. Rázuri de JIR Ingenieros Responsable de la construcción de la estructura de bambú: Maximiliano Galarza.

Descripción: Este proyecto fue respuesta a un encargo de la Municipalidad de Surco para albergar un espacio de intercambio cultural que se integre con su entorno inmediato y cumpla con las necesidades de confort y funcionalidad para conferencias y/o exposiciones abiertas.
De forma general, es una propuesta innovadora que promueve una arquitectura con un impacto ambiental reducido a través el uso de materiales eco-amigables como el bambú y la madera. El techo está compuesto de dos aguas separadas por un tragaluz cenital (por donde penetra una luz filtrada a través de cañas chancadas) que permite el escape del aire y provee de una ventilación natural efectiva del espacio. En los costados del auditorio, se encuentran persianas de bambú que ofrecen una protección solar y comparten el mismo lenguaje arquitectónico con los otros pabellones del parque. (Figuras 9 y 10)

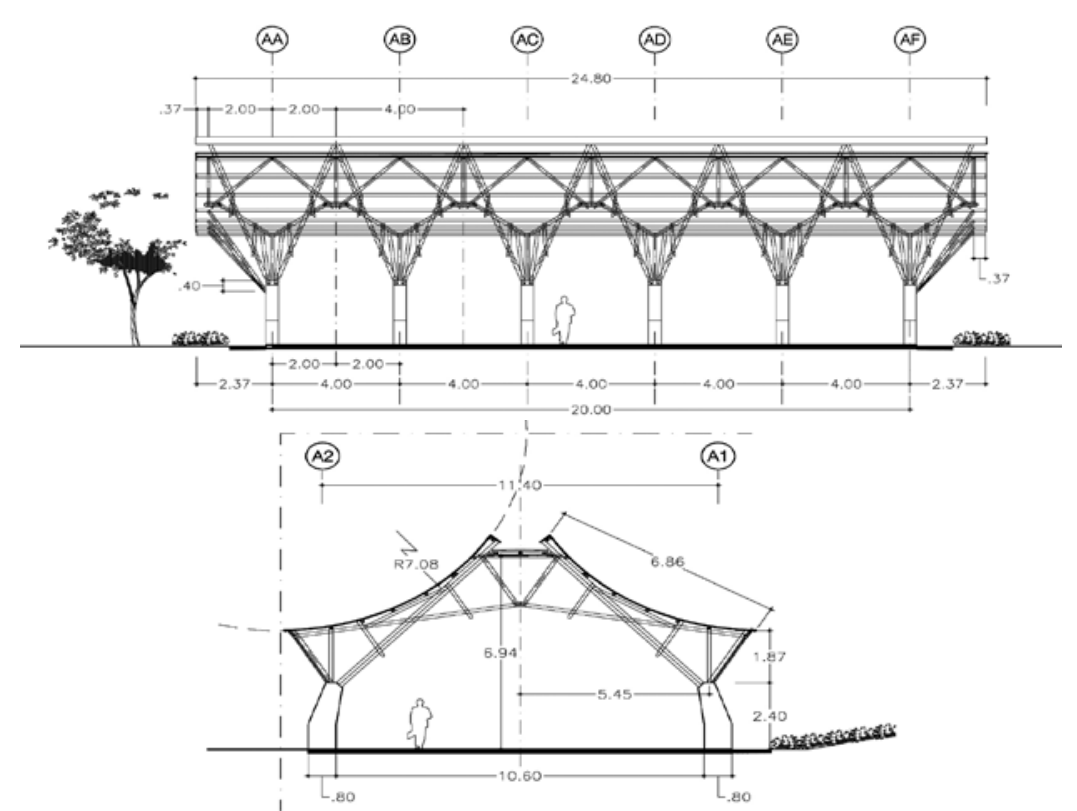

Figura 9. Cortes longitudinal y transversal del Auditorio de bambú Voces por el Clima 


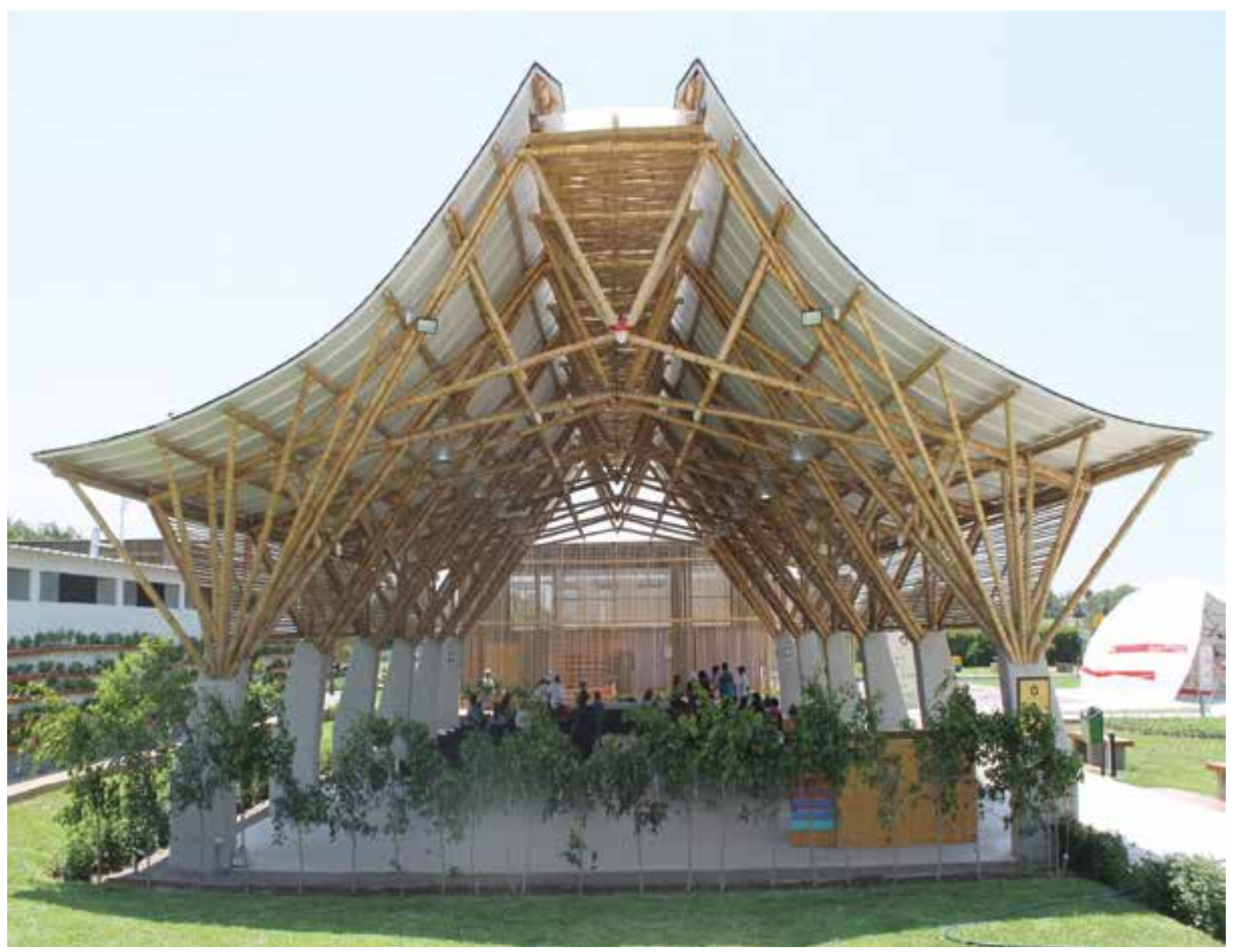

Figura 10. Auditorio de bambú Voces por el Clima

\section{Casa Voces por el Clima}

Área construida: $52 \mathrm{~m}^{2}\left(39.50 \mathrm{~m}^{2} \mathrm{de}\right.$ superficie útil) (Figuras 11 y 12)

Diseño: Arquitectos Y. Barnet, $\mathrm{F}$. Jabrane y D. Cataño del IVUC - FIA, USMP.

Cálculo estructural: Ing. H. Castro Responsables de la construcción: A.25 ARQSTUDIO SAC

Descripción: El diseño de esa casa demostrativa es una adaptación del concepto de vivienda social progresiva desarrollado por el IVUC para el concurso Construye para Crecer. Por lo tanto, responde a los parámetros del programa
Techo Propio. Este módulo de $4 \times 8 \mathrm{~m}^{2}$ está estructurado por paneles prefabricados de bambú tipo bahareque que se anclan sobre unos cimientos corridos de concreto. Las paredes no estructurales son compuestas de paneles prefabricados de madera en los cuales se elige disponer las aperturas en función de las necesidades específicas de cada proyecto (puertas, ventanas, persianas de ventilación). El objetivo es enseñar que una casa de bambú bien diseñada y construida es fresca, sismorresistente, cálida, estética, eco-amigable y sobre todo es durable si se le da el cuidado adecuado. 

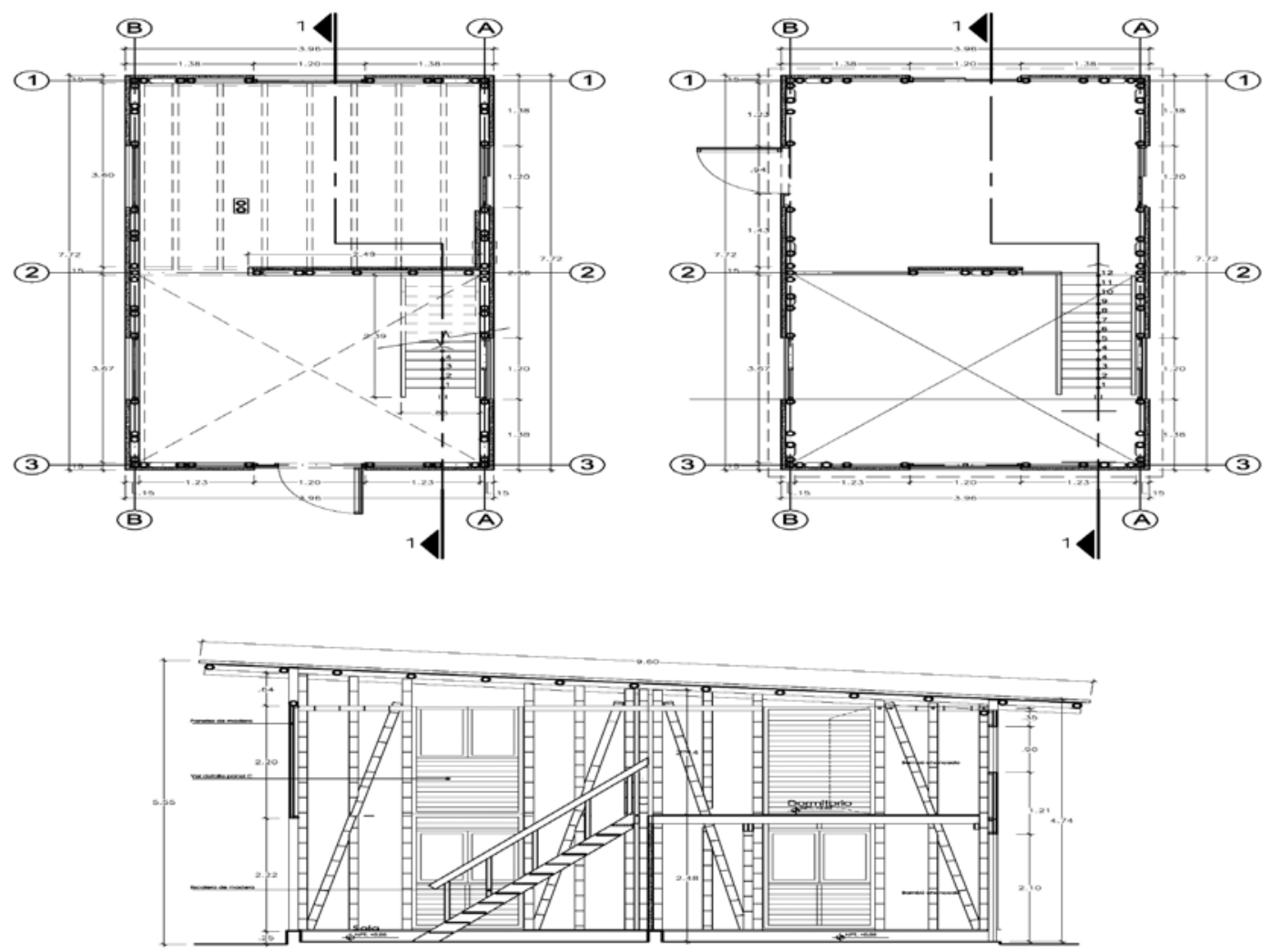

Figura 11. Plantas y Corte longitudinal de la Casa Voces por el Clima

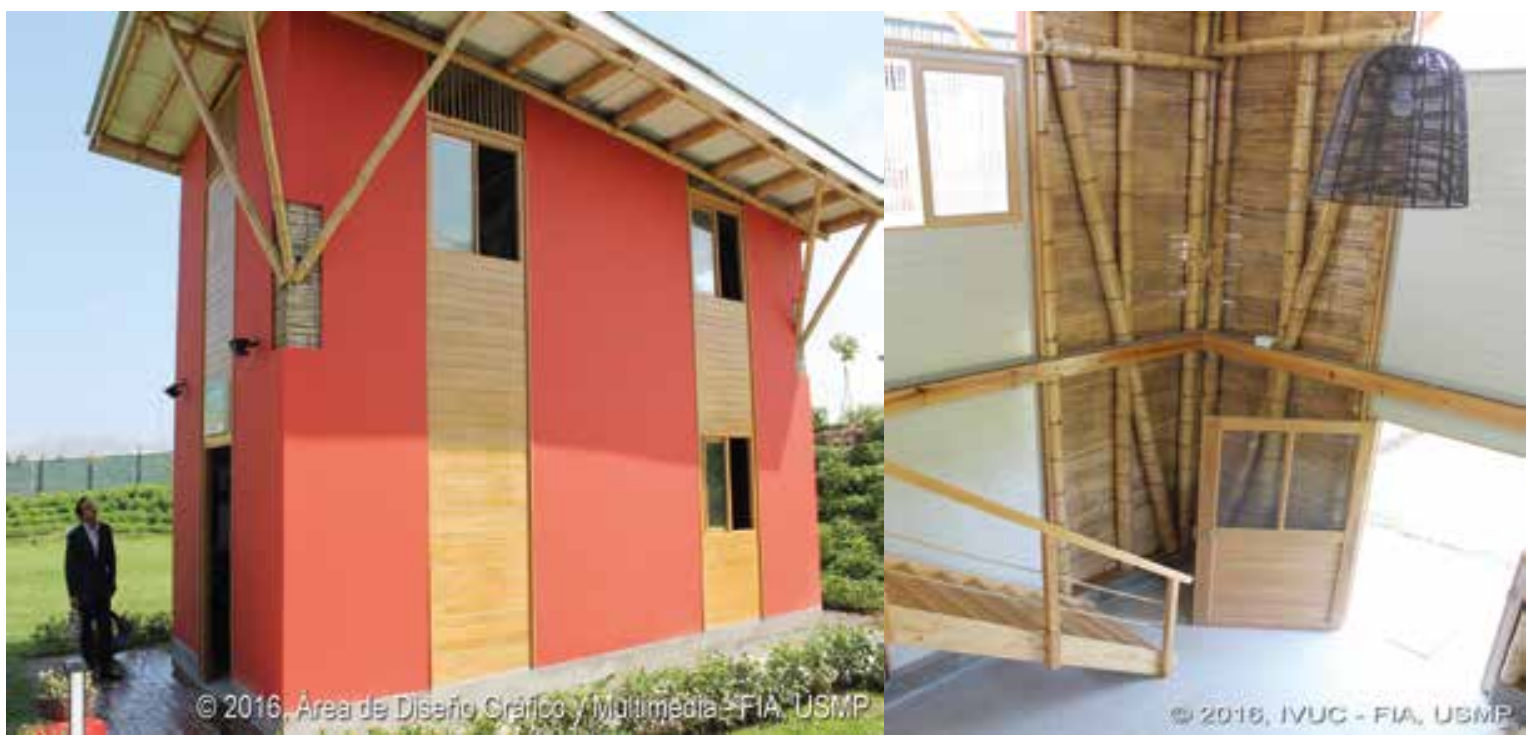

Figura 12. Casa "Voces por el Clima"

\section{Kiosco Móvil de bambú}

Área construida: $7.2 \mathrm{~m}^{2}$

Diseño: Arq. D. Cataño del IVUCFIA, USMP

Descripción: El diseño contempla dos bloques que cubren un área de $2.40 \mathrm{~m} \mathrm{x}$ $3.00 \mathrm{~m}$ (siendo el módulo base $1.20 \mathrm{~m} \mathrm{x}$
$3.00 \mathrm{~m})$, y se compone, estructuralmente, de bambú y pallets de madera que puede ser móvil y dividido según la necesidad. (Figuras 13 y 14). El estand de exhibición se complementa con las jabas plásticas de colores para la muestra de los productos que funcionan como anaqueles, repisas o 
mesa de atención. Un primer prototipo se construyó en el campus de la Facultad de Ingeniería y Arquitectura, Universidad
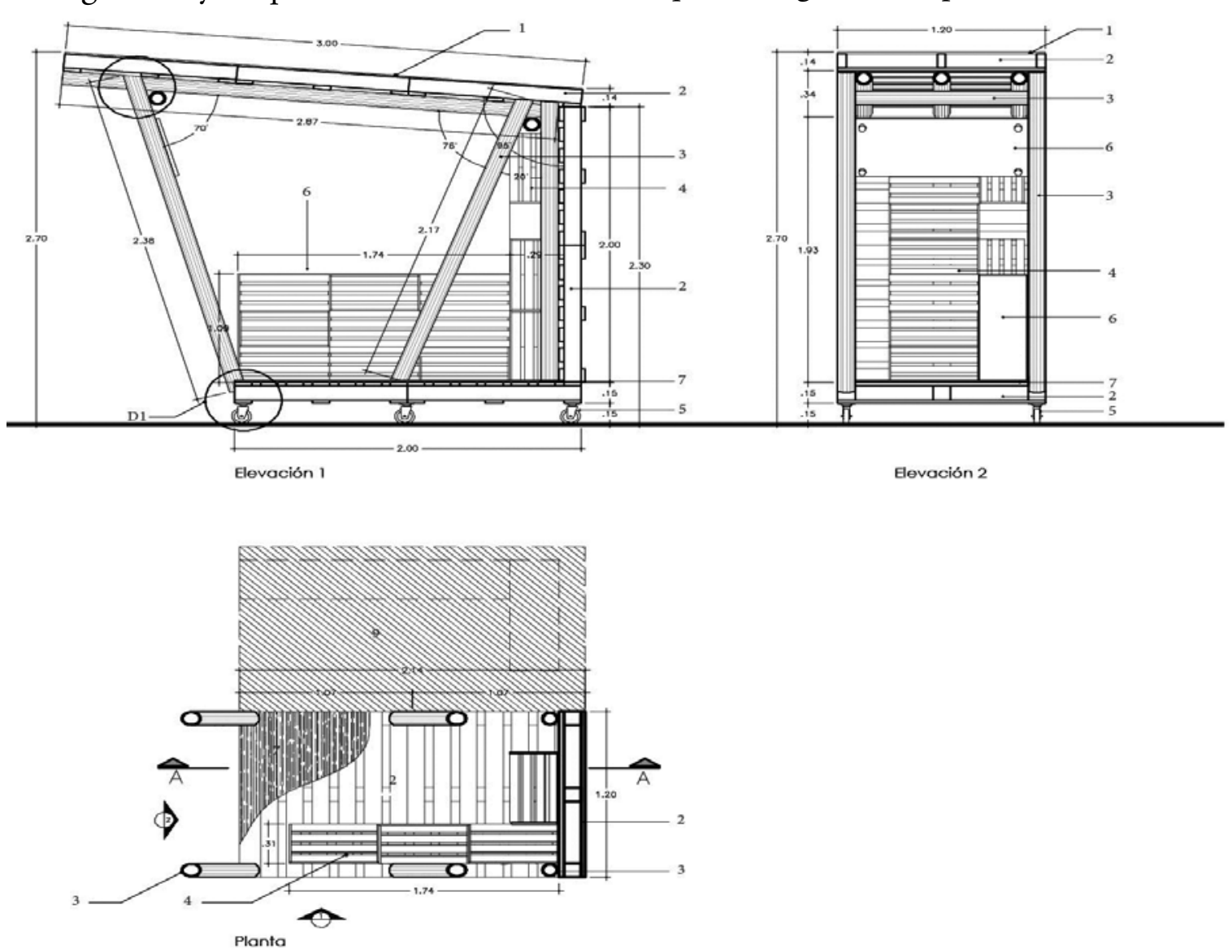

Figura 13. Plantas y corte del Kiosco Móvil de bambú

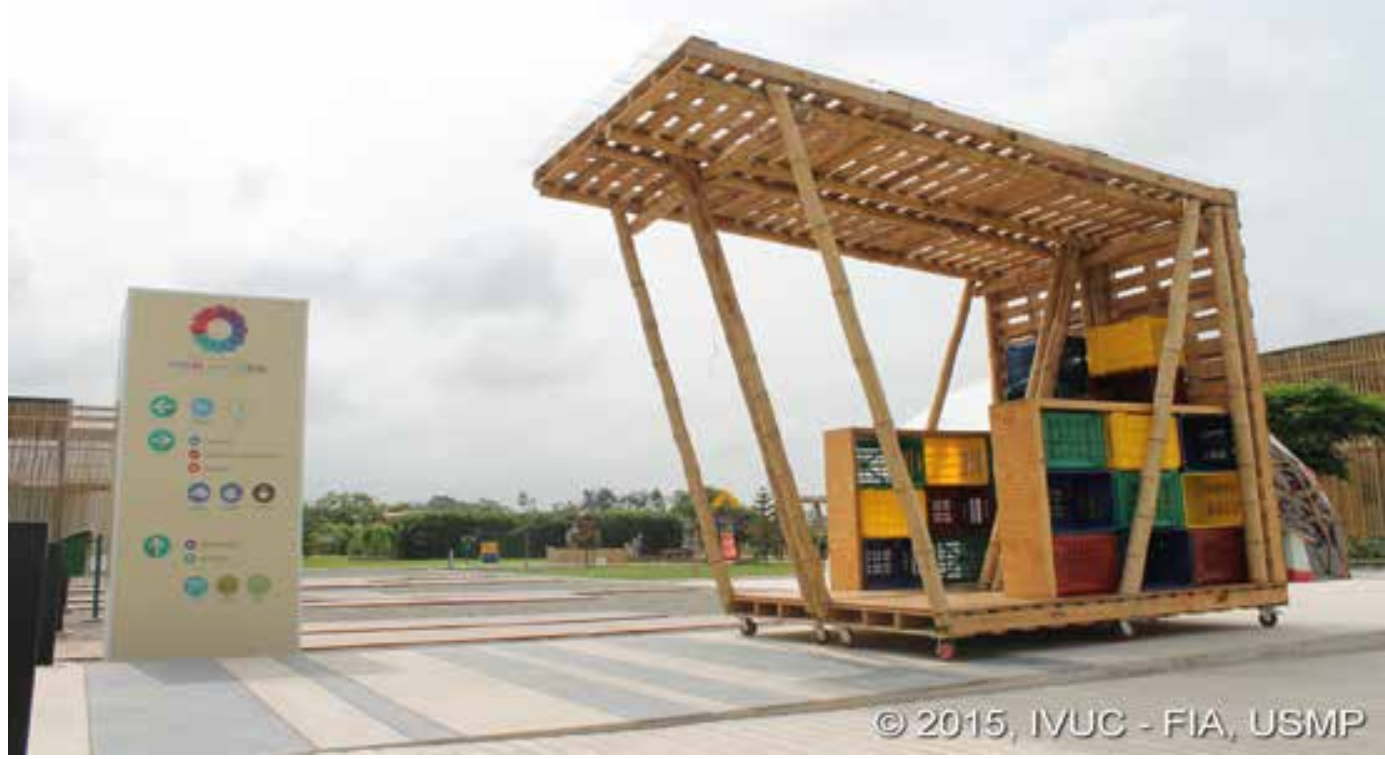

Figura 14. Kiosco Móvil de bambú 
Difusión de experiencias y conocimientos: eventos, capacitacíon y plataforma web

Con el fin de potenciar los proyectos demostrativos, así como seguir el proceso de promoción de las oportunidades del bambú, en el Perú, con la difusión de los últimos avances tecnológicos y creativos, El IVUC-USMP y el INBAR, organizaron, desde el ańo 2012, eventos donde se invitan a la mayoría de actores de todos los sectores para crear nuevas dinámicas y redes. El último, fue la "Jornada Acero Vegetal", con la colaboración de la Unión Europea, el Ministerio del Ambiente, la Municipalidad de Surco, el Colegio de Arquitectos Regional Lima, SERFOR del MINAGRI y FSC. Durante este evento, especialistas de varios sectores profesionales provenientes de Perú, Colombia, Ecuador y Francia, expusieron sus experiencias y las iniciativas exitosas en el sector de la cadena de valor del bambú. Las conferencias se realizaron en el auditorio del Parque Ecológico Voces por el Clima de Surco, y la jornada terminó con la inauguración de la casa de bambú "Voces por el Clima”, y se presentó esos ejemplos a un público interesado en participar de la cadena de valor del bambú.

Este evento fue complementado por el II Workshop Acero Vegetal, un curso sobre "Diseño y construcción de estructuras de Guadua Angustifolia", constituido por un taller de construcción dictado por los Arq. Jabrane y Barnet y un curso sobre el diseño estructural con Bambú dictado por la ingeniera colombiana Caori Takeuchi, una investigadora de fama mundial en estructuras de bambú. Con esos cursos teórico-prácticos, se buscó generar una red de profesionales capaces de obtener el mejor provecho del bambú, participar en el desarrollo de su cadena de valor, así como investigar e innovar para mejorar sus procesos de aprovechamiento y multiplicar sus usos.

Para facilitar la creación de redes, compartir información, y participar del fortalecimiento de la cadena productiva del bambú, a nivel nacional, el IVUC ha creado, en sociedad con el INBAR, el Centro del Bambú del Perú, una plataforma web (http://www.usmp.edu. pe/centro_bambu_peru) donde se da a conocer los actores e iniciativas, a nivel nacional, así como se comparte informaciones técnicas.

Toda esa estrategia de comunicación y actividades de promoción tienen que estar sustentadas por proyectos concretos de alta visibilidad, que dan pruebas tangibles de los beneficios del uso del bambú así como proyectos de investigación que fundamenten los avances y dinamizan la innovación.

\section{Resultados}

Desde sus aportes para la publicación de la Norma E100, en el Perú, el IVUC, a través las actividades y proyectos descritos anteriormente, ha tenido como objetivos masificar el uso del bambú en la construcción dentro una lógica de calidad y de desarrollo global de su cadena de valor.

De esas iniciativas se pueden destacar los siguientes resultados:

- La publicación, por parte del Fondo Mi Vivienda de cinco modelos de vivienda social progresiva unifamiliar con estructura de bambú. Los expe- 
dientes técnicos de cada uno están disponibles, de forma gratuita en cada municipio del Perú, y se pudo comprobar la validez de unos modelos a través de la construcción de prototipos.

- La capacitación de más de 200 personas sobre técnicas de construcción con bambú a través de workshop teórico- prácticos dirigidos a todos los profesionales de la construcción y público en general tres en Lima, tres en Chiclayo, uno en Iquitos, uno en Guayaquil-Ecuador y uno en Quito-Ecuador).

- La concientización de más de 500 personas sobre los beneficios del bambú y oportunidades de valor agregado con la organización de tres eventos de difusión en Lima y uno en Chiclayo, así como múltiples conferencias.

- Poner a disposición información técnica acerca del bambú, ejemplos de construcción en bambú a nivel nacional, y una lista de actores de la cadena de valor del bambú con la plataforma web del Centro del Bambú del Perú. Desde 2015, por grandes cantidades de visitas, está página web aparece en las tres primeras opciones de google cuando se hace una simple búsqueda con las palabras "bambú" y "Perú".

- Adaptación de un manual de construcción con bambú al contexto peruano que se puede descargar integralmente.

- Poner a disposición de un público masivo construcciones demostrativas perennes en un espacio público de Lima.

De esas experiencias, queremos también compartir las siguientes lecciones aprendidas:

- Existe una idea falsa que el uso del bambú significa que la construcción va a ser muy económica. Sin embargo, es importante clarificar que el uso del bambú no, necesariamente, permite bajar los costos de construcción; sino, ofrece nuevas posibilidades en el diseño arquitectónico para crear tipologías adaptadas a su ambiente, con un nivel de confort más alto que los modelos básicos de albañilería confinada, y capaces de construirse en zonas sísmicas con suelos de baja capacidad portante.

- A partir del análisis de costos de los proyectos desarrollados, resulta que el bambú ofrece una alternativa estructural competitiva, económicamente, para estructuras livianas con luces intermedias (entre 6 y 12 metros). Para el caso de las viviendas, el uso del bambú, en la estructura, no genera cambios muy significativos frente a la albañilería confinada ya que una gran parte del monto total de una casa está definido por otras partidas (cementación, losa, vanos, acabados, instalaciones, etc.).

- A partir de la recolección de las reacciones del público, se aprecia que el método más eficiente para cambiar la imagen del bambú (como material de construcción) en la mente de las personas es la experiencia concreta de visitar una obra construida con bambú, en la cual se pueda ver y tocar el material.

- Para los procesos de capacitación sobre técnicas constructivas con bambú, el método pedagógico basado en la práctica concreta de la construcción resulta el más eficiente, ya que permite al aprendiz darse cuenta de las características físicas del material (peso, dureza, flexibilidad, resistencia) y, a la vez, tomar seguridad en cuanto a la factibilidad de las técnicas explicadas 
de forma teórica.

- Si bien existe un interés creciente, por parte de los arquitectos, en introducir el bambú dentro de sus diseños, los ingenieros civiles demuestran todavía bastante desinterés y dudas en cuanto a su uso estructural.

\section{Conclusión}

Dentro de una lógica de desarrollo inclusivo y eco-responsable, el potencial del bambú, en el Perú, se posiciona como una evidencia, sobre todo, en uno de los países más vulnerables al cambio climático en que es urgente buscar soluciones para reducir la presión sobre los bosques. Masificar el uso del bambú, en el sector de la construcción, no significa, únicamente, bajar las emisiones de gases invernaderos, sino también generar ingresos económicos para las numerosas comunidades campesinas que cuentan con este recurso, todavía muy poco valorado.

Existe desde el año 2012, la Norma E100 Bambú que respalda la construcción formal en el Perú, lo que favorece el crecimiento de este sector que cuenta cada vez más con iniciativas por parte de entidades, tanto públicas como privadas, así como parte de ONG y de la academia. Sin embargo, los proyectos siguen siendo aislados y difíciles de llevar a cabo por la falta de institucionalidad, de materia prima de calidad y de profesionales preparados. Resulta muy importante que se crean sinergias entre los distintos actores y que se incentive una demanda cada vez más importante y exigente, en paralelo con una oferta que garantice la calidad de los productos y que favorezca, en primera instancia, a los productores.

En el campo de la construcción, se requieren proyectos construidos como ejemplares, cuya durabilidad y calidad arquitectónica real será el principal motor del cambio de imagen. Los proyectos realizados por el IVUC, que sean de vivienda social o de infraestructuras públicas han dado resultados muy positivos, tanto en el sector público como privado que empiezan a creer en el bambú e invertir con este material.

Por otra parte, sin tecnificación ni mejora de su valor agregado, no se puede pretender ampliar su campo de aplicación ni volverse un material competitivo dentro del mercado de la construcción, marcado por la omnipresencia del concreto y ladrillo que gozan, al contrario del bambú, de una imagen de calidad. Esta tecnificación tiene que empezar desde el manejo forestal y los procesos de poscosecha para asegurar la calidad y trazabilidad de la materia prima, pero sobre todo se tiene que mejorar su empleabilidad en la construcción que representa uno de los mayores mercados para ese material. Con el fin de lograr este objetivo, se requiere investigar y proponer nuevas técnicas de construcción. Para responder a este desafío, se está implementado, en el IVUC, un proyecto de investigación sobre Diseño de uniones y componentes industrializados para optimizar la construcción con bambú - Guadua, con la meta de introducir nuevos métodos de construcción a base de bambú que permitan participar de la masificación de su uso. Se invita a los investigadores interesados a participar con el IVUC de este proyecto. 


\section{Agradecimientos}

La construcción de los proyectos presentados, en este artículo fue posible gracias al apoyo de numerosas instituciones quienes nos acompañan en la labor de difundir alternativas sostenibles para la construcción. Para los proyectos detallados en este artículo, nuestro principal socio estratégico es la Red Internacional de Bambú y Ratán - INBAR.

También agradecemos a:

- Las empresas Ferias Multisectoriales, Sanlex SAC, Onduline, Constructora Grupo Cadillo, Gardini, Microcemento Italgrif, Koplast, Ceper Cables, Construtek, para el proyecto de la EXCON 2013.

- La empresa Tetrapak y la revista Arkinka, para el proyecto de la Feria Voces por el clima de la COP 20

- La ONG Socios en Salud y el programa de Responsabilidad Social de la USMP, para el proyecto de la casa en San Juan de Lurigancho

- El Ministerio del Ambiente, la Municipalidad de Santiago de Surco, la empresa TetraPak, para la obras en el Parque Voces por el Clima.

\section{Referencias}

Añazco, M. (2013). Estudio de vulnerabilidad del bambú (Guadua angustifolia) al cambio climático en la costa del Ecuador y norte Perú. Quito: INBAR.

Barnet, Y., \& Jabrane, F. (2013). Estudio de vulnerabilidad al cambio climático orientado a las viviendas del norte del Perú. INBAR.

Comisión Episcopal de Acción Social. (2009). Una estrategia de reconstrucción solidaria, participativa y democrática por terremoto. Lima: CEAS.

CORPEI - CBI. (2005). Perfil del producto bambú, proyecto CORPEI CBI "Expansión de la oferta exportable del Ecuador". Quito: CORPEI.

Espinoza, A. (2015). Estudio de la cadena desde la producción al consumo del bambú (Guadua angustifolia) en el Perú. Lima.
Fondo MiVivienda. (2016). Catalogó de Prototipos Construye Para Crecer II Edición. Lima: Fondo Mivivienda.

INEI. (2008). Censos nacionales 2007: XI de Poblacion y VI de Viviendas. Lima: INEI.

Janssen, J. J. (1981). Bamboo in building structure. Eindhoven.

Londoño, X. (2005). Aspectos generales de los bambúes americanos. Primer Congreso Mexicano del Bambú. Mexico.

Ministerio de Agricultura. (2008). Plan Nacional de Promoción del Bambú 2008-2020. Lima: Ministerio de Agricultura.

Ministerio de Agricultura y Riego. (2013). Perú forestal en números 2012. Lima. 
Ministerio de Agricultura y Riego. (2014). Perú forestal en números 2013. Lima: Dirección de Información y Control Forestal y de Fauna Silvestre del Ministerio de Agricultura y Riego.

Ministerio de Agricultura y Riego. (2015). Perú forestal en números 2014. Lima: Ministerio de Agricultura y Riego.

Ministerio de Vivienda, Construcción y Saneamiento. (2014). Prototipos de Vivienda progresiva. Lima: Fondo MIVIVIENDA.
Ministerio de Vivienda, Urbanismo y Construcción. (2012). E100 Bambú. Reglamento Nacional de Edificaciones. Lima, Perú.

Surco Mi hogar. (Octubre de 2016). Municipalidad de Surco. Obtenido de http://www.munisurco. gob.pe/surco_portal/municipio/ app/2016/10-octubre/19_(07oct)_visitantes_voces_por_el_clima_80300.html

U., J. A. (2014). De los "Materiales convencionales" a los "Eco materiales". Primer congreso Internacional Innovaciones con bambú. Guayaquil. 


\section{INVESTIGACIÓN BÁSICA}


